\title{
Denial, Media and Endurance in Infection Control in Kosova
}

\author{
Lul Raka ${ }^{1,2}$, Gjyle Mulliqi 1,2, Isuf Dedushaj ${ }^{1,2}$, Selvete Krasniqi ${ }^{1,2}$, Tahire Gjergij ${ }^{1,2}$, \\ Avdyl Krasniqi i,3, Drita Salihu ${ }^{1,2}$, Gazmend Spahija ${ }^{3}$ \\ ${ }^{1}$ National Institute of Public Health of Kosova, Kosova \\ ${ }^{2}$ Medical School, Prishtina University, Kosova \\ ${ }^{3}$ University Clinical Centre of Kosova, Kosova
}

\begin{abstract}
Nosocomial infections constitute an important public health problem in developing and transitional countries. Kosova is the poorest country in Europe and communicable diseases are a major health problem. The annual per capita government expenditure in health care is only $35 €$. Infection control in Kosova is in its infancy. The main challenges in this field are the lack of financial support and political commitment, an inadequate number of trained personnel, overcrowded wards, poor management and technological gap. In the past, infection control was limited to passive monitoring. Nosocomial infections were denied or hidden by hospital administrators. The public and mass media have had a great impact on the initiation of governmental activities in the field of safety and quality in health care institutions. A turning point in the approach to infection control was pressure from the mass media after an MRSA outbreak in the ICU during December 2005. Government has institutionalized infection control through the National Committee for Prevention and Control of Nosocomial Infections. Although devoid of any funding, the committee is making small steps towards ensuring safer care in health care institutions. Future steps in infection control should ensure the sustainability of any initiated activities.
\end{abstract}

\section{Introduction}

Kosova is located in South Eastern Europe and has experienced a turbulent history in the last two decades, which continues to have an impact on the healthcare system. The political situation culminated in war in 1999, when much of the health infrastructure was destroyed. Kosova has been under the protection of the United Nations since 1999. The Provisional Institutions of Self Governance has full responsibility for health care, education, environment and some other fields of governance. From February 2008 onwards, Kosova has been an independent state.

\section{Corresponding author}

Lul Raka, National Institute of Public Health of Kosova, Kosova, Email: Iulraka@hotmail.com 
Kosova has a surface of $10.887 \mathrm{~km}^{2}$ with a population of 2.1 million inhabitants, and is densely populated, with 220 inhabitants per $\mathrm{km}^{2} .{ }^{1}$ Kosova has the youngest population in Europe, with a mean age of 24.6 years. Only $6 \%$ of population is above 65 years of age. Women of childbearing age constitute $56 \%$ of the female population and unemployment is $60-70 \%$. A World Bank poverty report found that $50.3 \%$ of the population lives below the poverty line and $12 \%$ lives in extreme poverty. ${ }^{2}$ The estimated Gross Domestic Product per capita is $964 €$. Average monthly salaries are lowest in education $(174 €)$ and health care $(167 €)$.

\section{Health care}

Communicable diseases in Kosova remain the largest ongoing health care problem. Kosova has one of the highest infant mortalities (23.7 per 1000 births) and neonatal mortalities (25 per 1000 live births) in Europe. It is of great concern that $40 \%$ of hospital mortality is among infants. Only $45 \%$ of Kosovars consume safe drinking water. The annual incidence of TB is 53.4 per 100,000 inhabitants. Crimean Congo Haemorrhagic Fever, tularaemia and viral meningitis are endemic diseases in Kosova. The number of physicians per 1000 inhabitants is only 0.94 .

During the second part of last century, Kosova had a socialist healthcare system. After the war, the transition from old to more modern concepts of healthcare management presented a challenge to both healthcare staff and the population.

The Ministry of Health governs the National Healthcare System. The public health system is financed by the Kosova consolidated budget, of which healthcare receives only $9.5 \%$. In the absence of economic development, the Kosova consolidated budget is not likely to grow rapidly in the near future.

The goals of the healthcare system set out by the Ministry of Health are: a healthy start in life; improving the health of young people; improving mental health, managing the quality of care and developing human resources for health.

There are two categories of medical service available in Kosova: public and private. The public health service consists of primary family medicine, secondary medicine (five regional hospitals with an average of 561 beds and two small county hospitals) and a tertiary hospital - the University Clinical Centre of Kosova (UCCK) with 2344 beds. Bed occupancy averages around $75 \%$ with an average length of stay of about 12.5 days.

The Institute of Public Health (IPH) is in charge of developing the health strategy in the fields of epidemiology, health education and promotion, disease prevention and health information. The strategies developed by the IPH have to be approved and implemented by the Ministry of Health.

The private sector has grown dramatically in the recent years and is predominantly focused on diagnosis and treatment. Counselling or preventive medicine is virtually non-existent in the private health sector, in contrast to the public sector.

No health insurance system has as yet been established and this represents a key to improvement of health care sector at all levels.

The two main challenges in health care area in our country are the lack of financial support and the lack of political commitment. The World Health Organization published figures for national per capita government expenditures on healthcare shows that in Kosova this amount is only $\$ 43 .^{3}$ It is less than any of the other countries from former Yugoslavia: Slovenia (\$1274), Croatia (\$701), Macedonia (\$329). In comparison the highest expenditures are in USA (\$2549) and Norway (\$3118). The expenditure in Kosova is less than that in many African countries: Djibouti (\$48), Egypt (\$100), Gabon (\$170), Lesotho (\$84), Zimbabwe (\$47) and Namibia (\$252).

\section{Infection Control}

Nosocomial infections constitute a major public health problem worldwide. They result in high morbidity and mortality, prolonged hospital stays, greater use of antibiotics, and increased costs. ${ }^{4}$

Infection Control in Kosova is making its first steps. Coordination of activities between the three main bodies involved, the Ministry of Health, the hospitals and the National Institute of Public Health has 
improved in recent years. In the past, actions were only initiated as a response to the late stages of outbreaks. There was no anticipation of the possible risks of nosocomial infections and no strategy for their control and prevention. Hospital Infection Control committees existed only on paper. The epidemiology and hygiene departments had the power to inspect hospitals, but only within the limited fields of hospital hygiene, sterilization and disinfection and certain outbreak investigations. No other documented national data on Infection Control in hospitals were available. Moreover, nosocomial infections had sometimes been hidden by hospital managers. The knowledge level of health care workers and even managers regarding prevention and control measures for health care associated infections was limited.

The new concept of Infection Control as a specific discipline came to Kosova after the war, through an exchange program with an Infection Control team from Kingston, Canada. The first Kosovan article published in the field of nosocomial infection was on bacteraemia amongst paediatric patients in UCCK in 2002, and showed a crude mortality of $31 \%$ amongst newborns. ${ }^{5} \mathrm{~A}$ descriptive prevalence study on nosocomial infections in targeted high-risk areas was then undertaken in December 2003, again in UCCK. This study showed an overall prevalence rate of $17.4 \%{ }^{6}$

As in other developing countries, common problems in the field of infection control are lack of financial support, lack of political commitment, an inadequate number of trained personnel working in Infection Control, overcrowded wards, and insufficient equipment and supplies.

As a result, outbreaks of nosocomial infections in Kosovan health care institutions were common. The most common reported problems were staphylococcal skin infections in neonatal departments; ventilator associated pneumonia in Intensive Care Units (ICUs); sepsis with Pseudomonas aeruginosa in dialysis centres, contamination of liquid soaps; outbreaks of methicillin-resistant Staphylococcus aureus (MRSA) and extended-spectrum ß-lactamase (ESBL)-producing Gram-negative bacteria in ICUs and surgical departments. Outbreaks of nosocomial meningitis from multi-vial doses of anaesthetic medications were also reported.

Increased rates of infections with increased resistance from ICU samples were continuously identified in the microbiology laboratory. Following consultations with clinicians, reports were sent to hospital managers and also to the officials in the Ministry of Health. Unfortunately, the importance of these reports was underestimated by the stakeholders and they were not followed up with preventive measures.

\section{Media}

A turning point in the approach to nosocomial infections and Infection Control was an MRSA outbreak in an ICU at UCCK in December 2005. During that month an outbreak of MRSA emerged at the central ICU. During an audit in the ward it was found that there no soap or paper towels were available by the sinks. Also, some of the suction catheters were reused after insufficient disinfection. Investigation of clinical samples in the microbiology laboratory revealed an increased frequency of MRSA and multiresistant Gram negative bacilli that had the same phenotypic pattern in susceptibility testing. After aggregation of the data, and taking into consideration the previous events, a report was report with a recommendation to close the ICU ward until conditions had been rectified. This report was sent to all the executive officers from hospital managers to the Prime-minister. When the report reached the media, the resultant pressure caused infection Control to become a widely discussed matter of concern. In the meantime hospital administrators invited the sanitary inspectorate within the Ministry of Health to conduct an investigation. This resulted in the same recommendation, namely to close the unit. Thus media pressure seemed to have achieved the necessary result from government.

As a result of the debate provoked by the report in the media, newspapers and among health care workers (HCWs), the awareness of nosocomial infection by those involved was increased and the Ministry of Health of Kosova established the National Committee for Prevention and Control of Nosocomial Infections as the executive body to combat this modern challenge to health care. The key medical specialties and institutions were enrolled on that committee. 


\section{Activities}

The initial activities of this committee included translations of CDC definitions of nosocomial infections into Albanian. Resulting from the outbreaks in ICU, a comprehensive team of experts worked on hand hygiene recommendations. Occupational health was also one of the Committee's priorities. During April 2007 hepatitis B vaccination began for health care workers (HCW), with those not immunized in UCCK receiving a first dose of the vaccine. The next step envisaged would be to extend the Infection Control activities to the regional hospitals.

One of main objectives was developing cooperation between professional institutions that work in Infection Control. Initial cooperation was established and maintained with Kingston General Hospital in Canada. The International Federation for Infection Control (IFIC) handbook "Infection Control-basic concepts and training" was translated into Albanian and distributed as free elementary literature in Infection Control. Good cooperation was established also with the Infection Control Nurse association (ICNA - now Infection Prevention Society) from the United Kingdom and the Association of Professionals in Infection Control (APIC) from the USA, both of which donated kits of education material.

The Hospital Infection Society from the UK arranged a study visit by its experts in the field of sterilization and disinfection during October 2007 during which time seminars and recommendations were offered to local HCWs involved in this field.

The Kosovan government has now signed a pledge to combat health care associated infections that was initiated by WHO within its program of World Alliance for Patient Safety.

Research in the field of Infection Control remains one of the cornerstones for improving Infection Control efforts. An initial study was undertaken to estimate the knowledge, attitudes and practices of health care workers in Kosovan hospitals regarding nosocomial infections. ${ }^{7}$ Data were obtained from 350 respondents in four hospitals of which $39 \%$ were doctors and $61 \%$ nurses. Only $16.8 \%$ of respondents knew the complete definition of nosocomial infection, whereas $47 \%$ thought disinfection is the process of complete destruction of all forms of microbial life. Regarding collection of blood samples: $25 \%$ withdraw immediately after skin disinfection and $47 \%$ five seconds later. Sixty percent of HCWs were vaccinated against hepatitis B. Fifty-seven percent of HCW reported that they had suffered a needlestick injury but $26 \%$ of them did not report it.

Another prevalence study was initiated in the ICUs at UCCK. It showed that $68.7 \%$ of patients had nosocomial infections. Ventilator associated pneumonia was present in $80 \%$ of patients with nosocomial infections. ${ }^{8}$ A six month prospective study on surgical site infections based on the HELICS protocol ${ }^{9}$ during 2006 showed the incidence of $12 \% .{ }^{10}$ An audit of 50 areas used for sterilization (mainly surgical) was undertaken in UCCK. Dry heat ovens were used in 43 sites. ${ }^{11}$ Six sites did not report any method for monitoring the quality of the sterilization process. Instrument preparation made use of household cleaning agents in $75 \%$ of cases.

Another important form of research is participation in international collaborative studies. Some of these have involved genotyping nosocomial bacterial strains from ICUs in cooperation with the Centre for Clinical and Molecular Microbiology, University Hospital Centre, Zagreb, Croatia and typing of Pseudomonas aeruginosa strains in Kosova in collaboration with the Laboratory of Health-Care Associated Infection, Health Protection Agency, Centre for Infections, London, UK.

Kosova is part of the international nosocomial Infection Control consortium (INICC) through participation in the project: Prospective, multi-centre study evaluating costs, risk factors, and rates of nosocomial infections in ICUs, which includes 75 hospitals in 24 countries from four continents. Another project is the determination of the molecular profiles of community acquired MRSA strains in Kosova with the Genomic Research Laboratory in Geneva.

\section{Conclusions and future directions}

Kosova has already achieved the first two steps in improving Infection Control: recognition and appraisal of the problem. The next step will be the most difficult - intervention in the field now the problem has been identified. 
Future directions in the field of Infection Control in Kosova will focus on the following areas: sterilization, disinfection and environmental control, education of healthcare workers, occupational health, legislation and work on strategies, guidelines and policies on specific Infection Control issues. In facing the challenge of Infection Control, endurance will be essential.

\section{Competing interests}

The authors declare that they have no competing interests.

\section{Acknowledgement}

We thank Prof MMH Sewell and Dr Mary Packer for critical reading and correction of manuscript.

Part of this work was presented as a poster presentation at the 8th Congress of the International Federation of Infection Control, Budapest, Hungary 18 - 21 October, 2007.

\section{References}

1. Office of Statistics Prishtina, Kosova. Demographic, social and reproductive health situation in Kosova. 2005.

2. Statistics of Social Welfare in Kosovo 2007, Series 5: Social Statistics. Statistical Office of Kosova, Kosova Government 2007, 1-37.
3. Working together for health - The World Health Report 2006, World Health Organization, Geneva 2006; 147-49.

4. Wenzel RP. Global perspectives of infection control. In: Prevention and control of nosocomial infections, 4th edn. Philadelphia LWW 2003; 14-33.

5. Raka L, Mulliqi GJ, Dedushaj I, Pittet D, Binishi R, Ahmeti S. Nosocomial bacteraemia among paediatric patients in Kosova. Clin Microbiol Infect 2003; 9: 192.

6. Raka L, Zoutman D, Mulliqi GJ, et al. Prevalence of nosocomial infections in the high risk units at the University Clinical Center of Kosova. Infection Control and Hospital Epidemiology 2006; 27: 421-423.

7. Raka L, Kalenic S, Zoutman Z, et al. Knowledge, attitudes and practices of health care workers in Kosova hospitals regarding nosocomial infections (16th ECCMID, Nice, France 1-4 April, 2006), Clinical Microbiology and Infection 2006; 12(4): 84.

8. Spahija G, Mulliqi GJ, Raka L, et al. Prevalence of Nosocomial Infections in Adult Intensive Care Units at a Kosova Teaching Hospital. Infection Control and Hospital Epidemiology 2008; 29: 421-422.

9. Wilson J, Ramboer I, Suetens C. Hospitals in Europe Link for Infection Control through Surveillance (HELICS). Inter-country comparison of rates of surgical site infection - opportunities and limitations. Journal of Hospital Infection 2005; 65: 165170.

10. Raka L, Krasniqi A, Hoxha F, et al. Surgical site infections in an abdominal surgical ward at Kosova Teaching Hospital. J Infect Developing Countries 2007; 1(3): 337-341.

11. Raka L, Mulliqi-Osmani GJ, Vishaj A, et al. Sterilization practices at the University Clinical Centre of Kosova - time for action. Journal of Hospital infections 2006; 64(1): 3. 